\title{
Impacto de las concentraciones de ANA y sacarosa en el enraizamiento in vitro de Butia odorata (Barb. Rodr.) Noblick
}

\author{
Claudimar Sidnei Fior' ${ }^{1}$ Anaíse Costa Calil², Paulo Vitro Dutra de Souza' \& Sergio Francisco Schwarz' \\ 'Universidade Federal do Rio Grande do Sul, Programa de Pós-Graduação em Fitotecnia, Departamento de Horticultura e Silvicultura, \\ Faculdade de Agronomia. Av. Bento Gonçalves, 7712, CEP 91540-000, Porto Alegre, Rio Grande do Sul, Brasil. \\ 2Fundação Zoobotânica do Rio Grande do Sul, Jardim Botânico. Rua Dr. Salvador França, 1427, CEP 90690-000, Porto Alegre, \\ Rio Grande do Sul, Brasil. csfior@ufrgs.br
}

Recebido em 20. IX. 2015

Aceito em 30. IV.2018

DOI 10.21826/2446-8231201873102

\begin{abstract}
RESUMEN - El objetivo del estudio fue evaluar medios de cultivo buscando el desarrollo y formación de raíces en plantas de butiacero para la fase de aclimatización. Se utilizó el medio MS con 70\% de la concentración del nitrato de amonio y nitrato de potasio y $0,8 \%$ de agar. En el primer experimento se testaron concentraciones del ácido naftalenacético (ANA) en el medio. En el segundo, se evaluó el enraizamiento y el crecimiento de las plantas respecto a la variación de la concentración de sacarosa $\left(15,30\right.$ y 45 g.L. $\left.\mathrm{L}^{-1}\right)$ en medio añadido con $0,6 \mathrm{mg} . \mathrm{L}^{-1}$ del ANA. El tercer experimento se realizó con el fin de ajustar la concentración del ANA a partir de los resultados de los dos primeros estudios. Plantas de Butia odorata tienen su enraizamiento in vitro optimizado en medio con 0,3 hasta 0,9 mg. $\mathrm{L}^{-1}$ ANA combinado a concentraciones de sacarosa entre 30 y 45 g. $\mathrm{L}^{-1}$.
\end{abstract}

Palabras-clave: Arecaceae, bioma Pampa, butiacero, micropropagación

\begin{abstract}
Impact of ANA and sucrose concentrations on the in vitro rooting of Butia odorata (Barb. Rodr.) Noblick. The objective of this study was to evaluate the culture medium seeking the development and root formation of pindo palm seedlings for acclimatization. The MS medium were used at a concentration of $70 \%$ ammonium nitrate and potassium nitrate, and $0.8 \%$ of agar. In the first experiment, concentrations of naphthaleneacetic acid (ANA) added to the medium were tested. In the second, the rooting and growth of the seedlings were evaluated after varying the sucrose concentration $\left(15,30\right.$ and 45 g.L. $\left.\mathrm{L}^{-1}\right)$ in medium with $0.6 \mathrm{mg} . \mathrm{L}^{-1}$ of ANA. A third experiment was carried out to adjust the ANA concentration, based on the results of the first two tests. The rooting of Butia odorata seedlings were optimized in vitro in medium with 0.3 to 0.9 mg. $\mathrm{L}^{-1}$ of ANA, combined with concentrations of sucrose between 30 and 45 g.L. ${ }^{-1}$.
\end{abstract}

Keywords: Arecaceae, micropropagation, pindo palm, Pampa biome

\section{INTRODUCCIÓN}

El continente suramericano es uno de los más grandes centros de riqueza y diversidad biológica de la familia Arecaceae, pues cuatro de sus cinco subfamilias ocurren en dicha región (Geymonat \& Rocha 2009). En Brasil ocurren 39 géneros y 273 especies, 107 de ellas endémicas (Leitman at al. 2013). El género Butia se distribuye desde los estados de Bahia y Goiás, en Brasil, hasta Uruguay, Paraguay y Argentina (Marcato 2004). En Brasil ocurren 18 especies de ese género, siendo diez endémicas, distribuidas en los biomas Cerrado, Mata Atlántica y Pampa (Lorenzi et al. 2010, Leitman et al. 2013).

La especie Butia odorata (Barb. Rodr.) Noblick ocurre solamente en parte del Bioma Pampa, ubicado en el sur de Brasil y en Uruguay. Las plantas pueden alcanzar de ocho a diez metros de altura y una circunferencia de hasta $1,5 \mathrm{~m}$ a la altura del pecho. Sus hojas tienen un color gris, llegando al número de 32 hojas por planta, renovándose anualmente de 12 a 14 de ellas. Su floración ocurre en los meses de primavera-verano y la madurez de los frutos ocurre en verano y otoño (Pedron et al. 2004, Geymonat \& Rocha 2009, Pillar et al. 2009, Lorenzi et al. 2010).
Estudios recientes han demostrado el gran potencial de los frutos de Butia para producción de zumo, helados y otros derivados. Sin embargo, su cultivo comercial no ocurre debido a la falta de conocimiento sobre la producción y manejo de los plantones en escala comercial. Por otra parte, son incontables los casos de flagrantes de extracción ilegal de ejemplares adultos para uso en paisajismo, estando esta especie amenazada de extinción (Tonietto et al.2009, Rossato 2007, Geymonat \& Rocha 2009).

Hasta el presente, la propagación del butiacero ocurre solamente por semilla. Además, los métodos de superación de la dormancia de las semillas hasta hoy publicados no presentan alternativas eficientes y rápidas buscando atender satisfactoriamente a las demandas de la producción de plantones (Fior et al. 2011, 2013, Schlindwein et al. 2013).

El cultivo in vitro puede optimizar la producción de plantones, porque mejora el aprovechamiento de los propágulos y viabiliza la obtención de más plantones en menos tiempo. Wang et al. (2003) regeneraron plantones de Areca catechu a través de organogénesis en callos formados a partir de ápices caulinares de plantones cultivados in vitro, en medio de cultivo MS (Murashige \& Skoog 
1962) añadido del fosfato de sodio, niacina, peptona, N6bencilaminopurina (BAP) y tidiazuron (TDZ).

En las especies de Butia, el cultivo in vitro todavía se restringe al rescate de embriones zigóticos. Con ello se puede eliminar algunas dificultades en la formación de los plantones, una vez que el proceso de germinación de las semillas aún presenta muchos problemas. Por lo tanto, la generación de plantones a partir de embriones zigóticos se presenta ventajosa, pues permite un mejor aprovechamiento de las semillas disponibles y se generan lotes más homogéneos, aunque segregantes (Fior et al. 2011).

En estudios realizados por Ribeiro et al. (2011), embriones de $B$. odorata se desarrollaron mejor in vitro cuando se empleó el medio de cultivo MS conteniendo el $75 \%$ de las sales. Además, en las concentraciones del 50 al $75 \%$ se encontró menos oxidación.

Sin embargo, no se encontraron investigaciones que demuestren alternativas a la mejora del crecimiento y desarrollo de los plantones para su posterior aclimatización, por ejemplo, la formación de un sistema radicular satisfactorio, que permita una mejor adaptación a las condiciones ex vitro, elevando el porcentaje de supervivencia y el crecimiento de las mismas.

La presente investigación buscó evaluar componentes del medio de cultivo que viabilicen el desarrollo y la formación de raíces en plantones de Butia odorata, preparándolas para la fase de aclimatización.

\section{MATERIALES Y MÉTODOS}

Plantas obtenidas a través del desarrollo de embriones in vitro se emplearon como explantes. Los embriones se extrajeron de semillas cosechadas de frutos de diez plantas de una misma población ubicada en el ciudad de Encruzilhada do Sul $\left(30^{\circ} 25^{\prime} 35^{\prime \prime}\right.$ 'S y $52^{\circ} 40^{\prime} 39^{\prime \prime} \mathrm{O} ; 440$ $\mathrm{m}$ de altitud). En la fase inicial in vitro, los embriones se mantuvieron en medio de cultivo MS con 3 g.L.- de sacarosa, $0,8 \%$ de agar, $\mathrm{pH} 5,8$, por períodos entre 100 y 360 días, subcultivados a cada 90 días.

Como medio para las tres investigaciones se utilizó MS con $70 \%$ de la concentración del nitrato de amonio y del nitrato de potasio y de la sacarosa, añadido del $0,8 \%$ de agar; $\mathrm{pH} 5,8$. Se utilizó como contenedores de vidrio, tipo snap cap, con capacidad para $200 \mathrm{~mL}$, siendo que cada contenedor se llenó con $33 \mathrm{~mL}$ del medio de cultivo.

Para la instalación de los experimentos, se homogenizaron los plantones en largo, a través de corte con lámina de bisturí a $5 \mathrm{~mm}$ bajo de la altura del cuello. En seguida se establecieron las plantas en los contenedores de vidrio en sus respectivos tratamientos, quedándose inmersas en el medio de cultivo hasta cerca de $5 \mathrm{~mm}$ arriba de la altura del cuello. La sala de incubación era climatizada en $25 \pm 3{ }^{\circ} \mathrm{C}$ y con fotoperíodo de 16 horas, irradiancia luminosa del $22 \mu \mathrm{mol} . \mathrm{m}^{-2} . \mathrm{s}^{-1}$.

Tras los 70 días del establecimiento, se evaluaron variables del desarrollo y enraizamiento de los plantas, además de la emisión y crecimiento de hojas, y masa media de los plantas en cada contenedor.

\section{Concentraciones de auxina vs. edad de las plantas}

Se evaluaron las siguientes concentraciones del ácido naftalenacético (ANA) añadidas al medio básico MS antes da corrección del $\mathrm{pH}$ y del autoclavado: 1) control (sin

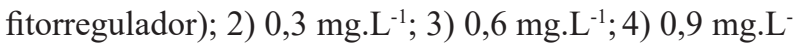
${ }^{1}$; 5) 1,2 mg.. $\mathrm{L}^{-1}$. Se utilizó la concentración del 20 g.L. $\mathrm{L}^{-1}$ de sacarosa.

El diseño experimental fue completamente casualizado en esquema factorial $5 \times 4$, considerándose como factor A la concentración de ANA $\left(0,3 ; 0,6 ; 0,9\right.$ y 1,2 mg. $\left.\mathrm{L}^{-1}\right)$ y como factor B la edad de las plantas, o sea, el tiempo desde la germinación hasta la instalación de la investigación, siendo: B1: 370 días, B2: 280 días, B3: 190 días y B4: 100 días. Para cada parcela se utilizaron cinco contenedores con cinco plantas en cada uno, totalizando 500 plantas.

\section{Concentraciones de sacarosa en el medio de cultivo}

Se evaluaron las concentraciones del $15 ; 30$ y 45 g.L $\mathrm{L}^{-1}$ de sacarosa en el medio de cultivo. Al medio básico se añadió también el 0,6 mg. $\mathrm{L}^{-1}$ de ANA.

Todas las plantas utilizadas se produjeron del desarrollo de embriones in vitro (estudio I), todos con 190 días desde su germinación.

El diseño experimental fue completamente casualizado con nueve contenedores por parcela, cada uno teniendo 5 plantas (total de 135 plantas).

\section{Ajuste de la concentración de auxina}

Una tercera investigación se realizó buscando ajustar concentración del fitohormoio ANA, tras los resultados de los estudios anteriores.

Al medio básico MS se añadieron el $45 \mathrm{~g} . \mathrm{L}^{-1}$ de sacarosa y tres concentraciones del ANA: 0,$3 ; 0,6$ y 0,9 mg. $\mathrm{L}^{-1}$, constituyendo los tres tratamientos.

El diseño experimental fue en bloques casualizados, teniendo como factor de bloque la edad de los plantones, desde la germinación de los embriones: bloques 1, 2 y 3 compuestos por las plantas que tenían 280, 190 y 100 días, respectivamente. Se utilizaron cinco contenedores por parcela, cada uno de ellos teniendo cinco plantas (total de 225 plantas).

Los datos de cada variable de los tres estudios se analizaron cuanto a la distribución normal (Test de Kolmogorov-Smirnov) y igualdad de las variancias (Test de Levene). Se trasformaron cuando necesario, según cada caso, los cuales se indican en la presentación y los resultados. En seguida, se realizó el análisis de varianza paramétrica o no paramétrica. Cuando la varianza fue significativa, se procedió el análisis de comparación de medias por el test DMS (5\%) y regresión de las variables respecto a la concentración de los componentes de los medios de cultivo evaluados en cada estudio, y test de correlación. 


\section{RESULTADOS}

\section{Concentraciones de auxina vs. edad de las plantas}

La supervivencia de las plantas fue alta al final del período de ejecución de la investigación, variando del 97 al $100 \%$, con media general del 98,8\% (Tabla 1). En ausencia del ANA en el medio de cultivo (control) el porcentaje de plantas enraizadas fue de un $43 \%$, con media de 1,36 raíces por planta.

Al añadirse ANA, independientemente de su concentración, se encontró una respuesta positiva y significativa con respecto al porcentaje de plantas enraizadas, número de raíces formadas, largo de hojas y masa fresca de las plantas, lo que demuestra que ese fitorregulador estimula la morfogénesis en $B$. odorata (Fig. 1).

En los medios de cultivo con auxina se verificó la formación de callos en la base de las plantas, siendo su incremento directamente proporcional a su concentración, suplantando en un $20 \%$ en las plantas que se cultivaron en el medio con 1,2 mg. $\mathrm{L}^{-1}$. En todas las plantas con callo se presentaban raíces bien desarrolladas y en número significativamente superior al control.

Para algunas variables hubo diferencia significativa entre las edades de las plantas en el momento de la instalación de la investigación. Plantas con edad de 180 y 360 días in vitro presentaron un porcentaje más grande de enraizamiento. El largo más grande de las plantas se obtuvo en aquellos con edad de 90 días y la masa fresca fue superior en aquellos con 180 días. Aún así, se necesitan más estudios con estas variables. No se verifico interacción significativa entre la edad de las plantas y la concentración de auxina en el medio de cultivo para ninguna de las variables en estudio (Tabla 1).

A través del análisis de correlación se verificó diferencias significativas positivas entre la masa fresca de las plantas con: largo de hojas, número de raíces, porcentaje de plantas enraizadas y de plantas con callo (datos que no se muestran). Esta relación se esperaba, una vez que la mayor expresión de las estructuras desarrolladas por las plantas genera una mayor masa de las mismas (Fig. 2).

Tras verificarse la correcta concentración del ANA buscando el enraizamiento de las plantas in vitro, surgió la necesidad de investigar el efecto de diferentes concentraciones de sacarosa en el medio de cultivo, una vez que informaciones de literatura indican que concentraciones más elevadas, en comparación a la usual para el medio de cultivo MS, son más favorables para el enraizamiento in vitro de palmeras (Badawy et al., 2005; Lédo et al., 2007).

Al final del período de investigación se logró 100\% de supervivencia de las plantas, independientemente de las concentraciones de sacarosa en el medio de cultivo. Los datos correspondientes a las variables porcentaje de plantas enraizadas, porcentaje de plantas con callo y número de raíces por planta no presentaron distribución normal, aunque los datos fueron trasformados. Por lo tanto, esas variables se analizaron a través del ANOVA no-paramétrica (test de Kruskal-Wallis) (Tabla 2).

El porcentaje de enraizamiento difirió entre las concentraciones de sacarosa. Se enraizaron un $80 \%$ de los plantones bajo la concentración del 15 g. $\mathrm{L}^{-1}$ de sacarosa, estadísticamente inferior a las otras dos concentraciones, que presentaron el 100\% de enraizamiento (Tabla 2). Semejante resultado se verificó para la variable masa fresca, aunque pueda estar solamente reflejando la masa más pequeña de las plantas que no se enraizaron.

Otra variable que presentó resultado superior en las más altas concentraciones de sacarosa fue el largo de raíces, cuyo incremento fue directamente proporcional a la concentración de sacarosa (Tabla 2).

El número de raíces no se alteró significativamente respecto al aumento de la concentración de la sacarosa en el medio de cultivo (Tabla 2). Eso indica que, en el rango estudiado, no se altera la rizogenesis en plantas de B. odorata in vitro.

En algunas plantas se observaron hojas senescentes, con color amarillo y porción con necrosis. Entre tanto, el porcentaje medio de plantas en esa condición fue bajo, no superando un 5\% y el análisis no-paramétrico no apuntó diferencias significativas para esa variable.

También se verificó la formación de callo en la base de algunas plantas, independiente de la concentración de la sacarosa. Pero estos callos tenían tamaño reducido y no impidieron la formación de raíces.

\section{Ajuste de la concentración de auxina}

Tras el análisis de los resultados de los dos estudios anteriores se dedujo la hipótesis de que la combinación entre los tratamientos de los mismos podría resultar en respuestas diferentes respecto a los dos individualmente. Por eso, para

Tabla 1. Enraizamiento in vitro de plantas de Butia odorata con diferentes edades bajo medio de cultivo con diferentes concentraciones del ácido naftalenacético.

\begin{tabular}{lccccccc}
\hline & Vivas (\%) & $\begin{array}{c}\text { Con formación } \\
\text { de callo (\%) }\end{array}$ & Enraizamiento (\%) & $\begin{array}{c}\text { Número de } \\
\text { raíces }\end{array}$ & $\begin{array}{c}\text { Largo de } \\
\text { raíces (mm) }\end{array}$ & $\begin{array}{c}\text { Largo de } \\
\text { hojas (mm) }\end{array}$ & $\begin{array}{c}\text { Masa Fresca } \\
(\mathrm{mg})\end{array}$ \\
\hline Transformación & $*$ & Raíz (x+100) & Asen [Raíz (x/100)] & Raíz (x+1) & Raíz (x) & - & - \\
Valor P (Concentraciones) & $>0,2$ & $<0,001$ & $<0,001$ & $<0,001$ & 0,466 & 0,028 & $<0,001$ \\
Valor P (Edad de plant.) & 1 & 0,122 & $<0,001$ & 0,415 & 0,044 & 0,001 & 0,042 \\
Interacción & - & 0,711 & 0,071 & 0,051 & 0,06 & 0,140 & 0,395 \\
Media General & 98,8 & 8,6 & 72 & 2,08 & 1,16 & 7,01 & 830 \\
CV (\%) & - & 4,44 & 27,52 & 16,94 & 22,55 & 17,77 & 23,31 \\
\hline
\end{tabular}

* Análisis no-paramétrica (test de Friedman) 


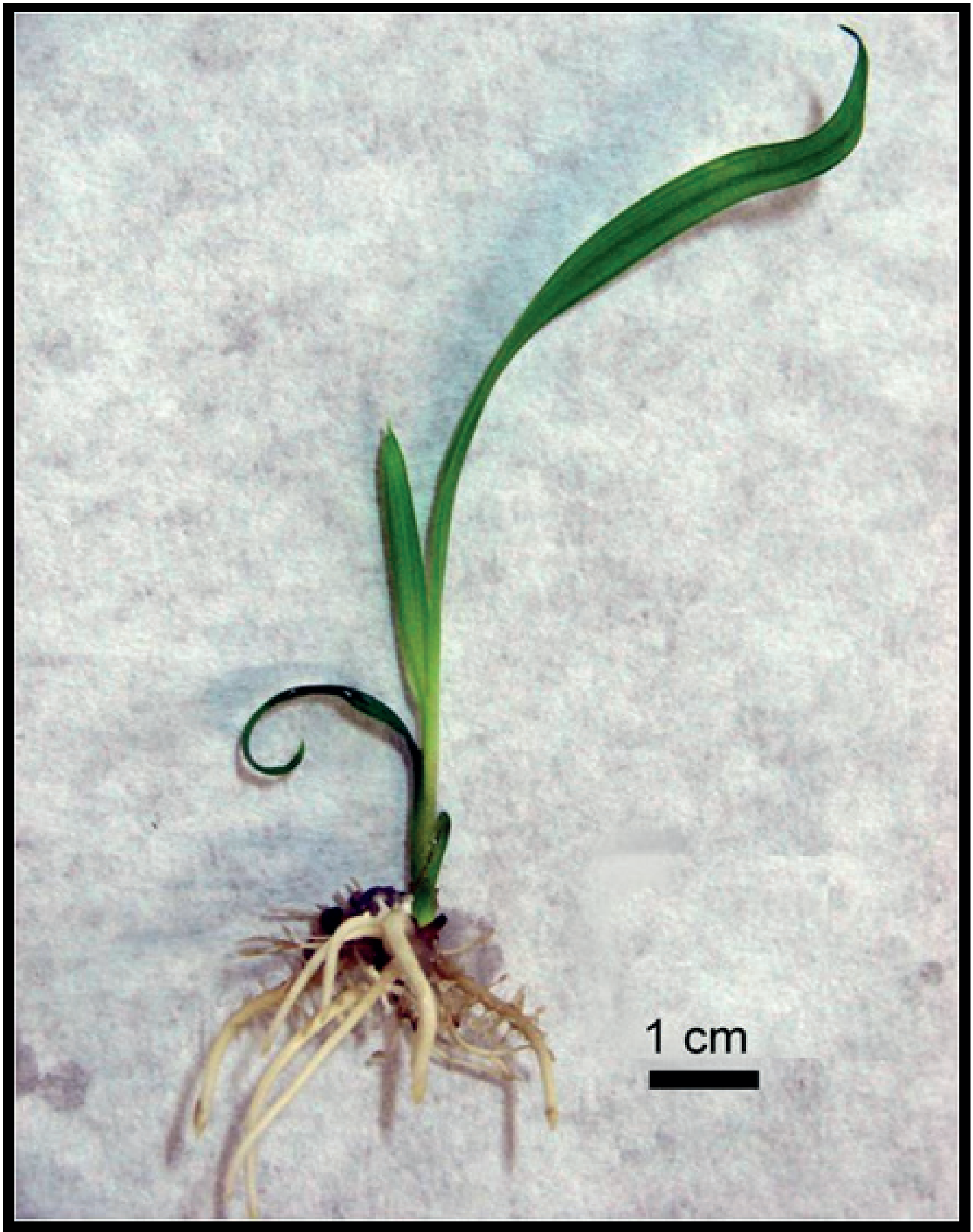

Fig. 1. Planta de Butia odorata enraizada in vitro en medio de cultivo con ácido naftalenacético $\left(0,6 \mathrm{mg} \cdot \mathrm{L}^{-1}\right)$.

el presente estudio se combinó la concentración de sacarosa al 45 g. $\mathrm{L}^{-1}$, tras pequeñas variaciones en la concentración del ANA, según los resultados del primer estudio.

La supervivencia de los plantones se mostró elevada, sin diferencias estadísticas entre los tratamientos, con media general del 97,7\% (P=0,606). Además, no hubo diferencia significativa para las variables porcentaje de plantas enraizadas, largo de raíces y masa fresca de plantas, con medias del $77,8 \%$, $2,47 \mathrm{~cm}$ y $1,63 \mathrm{~g}$, respectivamente $(\mathrm{P}>0,05)$.

El número de raíces por planta sufrió influencia directa de la concentración de auxina ( $\mathrm{P}<0,001)$. La ecuación de regresión indica una relación directa creciente entre 

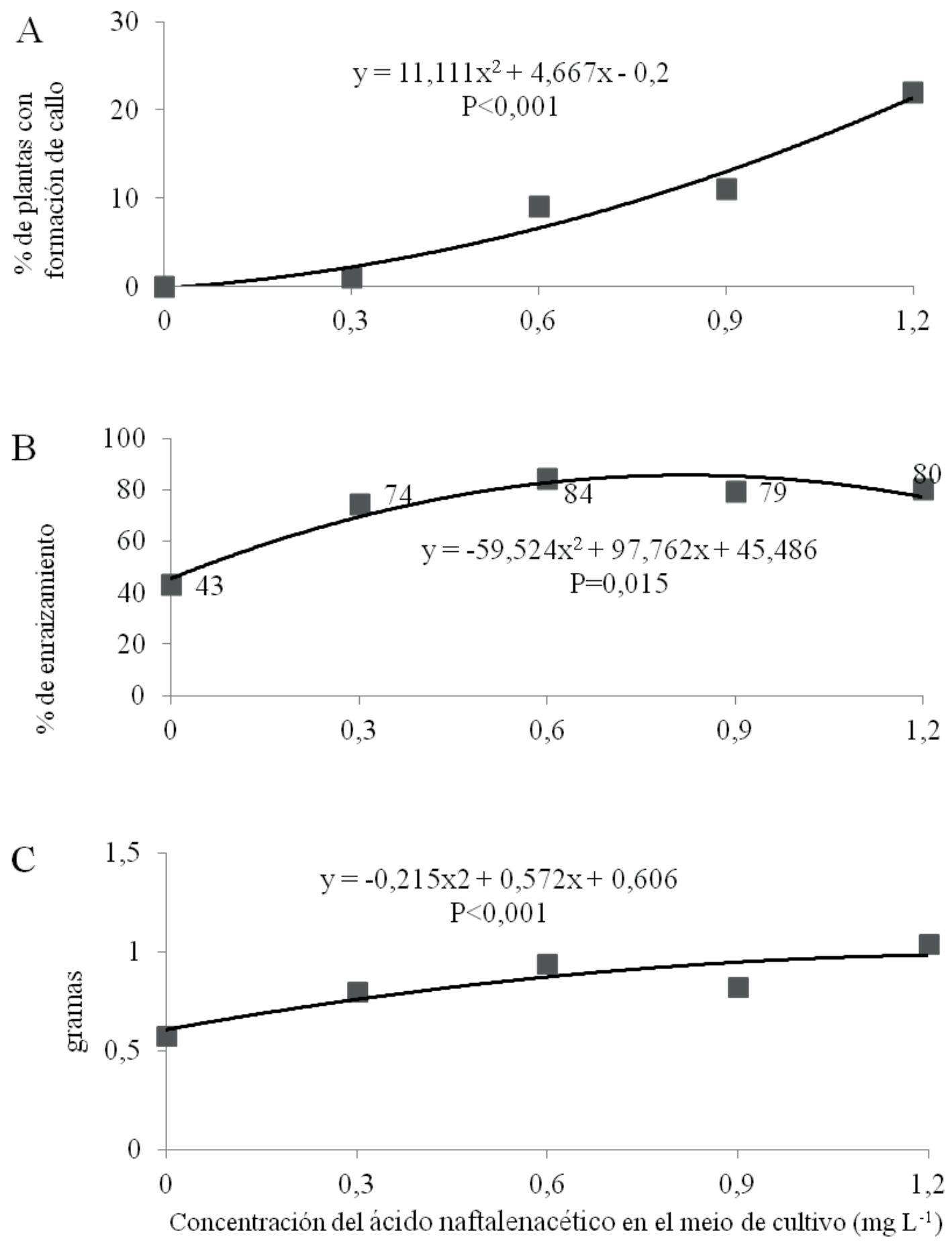

Figs. 2A-C. Enraizamiento in vitro de plantas de Butia odorata sometidos a los medios de cultivo con diferentes concentraciones del ácido naftalenacético. A. porcentaje de plantas con callo; B. porcentaje de plantas enraizadas; C. masa fresca de plantas.

esta variable y la concentración del ANA en el medio de cultivo (Fig. 3).

El largo de las hojas presentó respuesta inversamente proporcional a la concentración de la auxina en el medio de cultivo. Sin embargo, el desarrollo de las hojas fue importante mismo en las más bajas concentraciones del ANA, con media entre 4,88 y $6,5 \mathrm{~cm}$, en los tratamientos con menor y mayor desarrollo, respectivamente (Fig. 3). 
Tabla 2. Enraizamiento in vitro de plantas de Butia odorata en medio de cultivo con 0,6 mg.L ${ }^{-1}$ del ácido natalenacético y distintas concentraciones de sacarosa.

\begin{tabular}{|c|c|c|c|c|c|c|c|c|c|c|c|c|}
\hline $\begin{array}{l}\text { Trat }\left(g . L^{-1}\right. \\
\text { sacarosa) }\end{array}$ & Vivas (\%) & $\begin{array}{c}\text { Plantas con } \\
\text { callo }(\%)\end{array}$ & $\begin{array}{c}\text { C/ hojas } \\
\text { Senescentes }(\%)\end{array}$ & \multicolumn{2}{|c|}{$\begin{array}{c}\text { Enraizamiento } \\
(\%)\end{array}$} & $\begin{array}{l}\mathrm{N}^{\circ} \text { de raíces } \\
\text { por planta }\end{array}$ & \multicolumn{2}{|c|}{$\begin{array}{l}\text { Largo de las } \\
\text { raíces }(\mathrm{cm})\end{array}$} & \multicolumn{2}{|c|}{$\begin{array}{l}\text { Largo de las } \\
\text { hojas }(\mathrm{cm})\end{array}$} & \multicolumn{2}{|c|}{$\begin{array}{c}\text { Masa fresca } \\
(\mathrm{g} / \text { planta })\end{array}$} \\
\hline 15 & 100 & 8,89 & 4,44 & 80 & $\mathrm{~b}^{*}$ & 2,32 & 0,81 & $\mathrm{c}$ & 4,88 & $\mathrm{c}$ & 0,726 & $\mathrm{~b}$ \\
\hline 30 & 100 & 6,67 & 2,22 & 100 & $\mathrm{a}$ & 3,02 & 2,13 & b & 5,39 & b & 1,032 & $\mathrm{a}$ \\
\hline 45 & 100 & 2,22 & 0,00 & 100 & $\mathrm{a}$ & 2,98 & 3,26 & $\mathrm{a}$ & 5,96 & $\mathrm{a}$ & 1,092 & $\mathrm{a}$ \\
\hline
\end{tabular}

*Medias seguidas por misma letra en la columna no defieren estadísticamente por el test DMS (5\%).**Test Kruskal-Wallis

\begin{tabular}{lccccccc}
\hline Análisis & - & ----------- & ANOVA no-paramétrica** & ----------- & -------------------- ANOVA paramétrica------------------------ \\
\hline Media & 100 & 5,93 & 2,22 & 93,33 & 2,77 & 2,07 & 5,41 \\
Valor P & - & 0,456 & 0,338 & $<0,01$ & 0,096 & $<0,01$ & 0,048 \\
CV $(\%)$ & - & - & - & - & 26,3 & 29,18 & 17,18 \\
\hline
\end{tabular}

\section{DISCUSIÓN}

Las plantas de $B$. odorata obtenidos a partir de embriones zigóticos germinados in vitro y mantenidos en el medio sin fitorregulador, mostraron pocas raíces y estas presentaron gran variabilidad en su longitud. En estudios anteriores (datos no publicados), se verificó que plantas con esta característica se manejan con dificultad en la fase de cambio a sustratos (aclimatización), al menos que se corten las raíces, lo que, según Meerow \& Broschat (2011), no se indica para palmeras. Además, de acuerdo con Asemota et al. (2007), el establecimiento de un sistema radicular efectivo en palmeras producidas in vitro es esencial para el suceso posterior a la aclimatización, cuando alcanzan condiciones autotróficas.

Las concentraciones de la auxina estimularon la formación de raíces. La media de enraizamiento en los medios con el ANA fue del $79 \%$. De acuerdo con el análisis de regresión, el porcentaje de enraizamiento presentó tendencia cuadrática significativa en respuesta a la concentración del ANA. La concentración de $0,6 \mathrm{mg} . \mathrm{L}^{-1}$ proporcionó la más alta media. Entre tanto, por la ecuación da regresión, el punto de mayor respuesta para esa variable fue de $0,82 \mathrm{mg} . \mathrm{L}^{-1}$ del ANA(Fig. 2). Resultados semejantes fueron alcanzados por Badawy et al. (2005) en trabajos con el enraizamiento in vitro de Phoenix dactylifera. Sin embargo, para esa especie, la concentración que presentó respuestas superiores fue de $1,5 \mathrm{mg} . \mathrm{L}^{-1}$ del ANA.

Aunque el análisis de la varianza apuntó diferencia significativa entre las concentraciones del ANA para las variables número de raíces por planta y largo de hojas, el análisis de regresión no presentó significancia estadística. Por lo tanto, la presencia del ANA fue favorable, pero sin variar significativamente entre sus concentraciones.

También se constató una correlación positiva entre el largo de hojas y el número de raíces, lo que comprueba que las plantas con mayor formación de raíces también presentan mayor crecimiento de la parte aérea. Eso es muy importante, una vez que para la aclimatización, hay necesidad de que las plantas presenten desarrollo satisfactorio también de la parte aérea.

La presencia del ANA en el medio de cultivo no incrementó el largo de raíces. Ese resultado puede ser favorable bajo el punto de vista del preparo de la planta para la aclimatización, pues plantas con las partes aéreas bien desarrolladas, además de raíces numerosas y cortas se pueden establecer mejor en el sustrato de aclimatización. Además, siendo una especie monocotiledóneas, el número de raíces es más importante que el largo. Sin embrago, hay la necesidad de se obtener más informaciones respecto a la respuesta de las plantas al ambiente de aclimatización $\mathrm{y}$, consecuentemente, su supervivencia.

La presencia de una fuente de carbono y energía en el medio de cultivo es esencial para el desarrollo de las plantas, puesto que la fotosíntesis es limitada in vitro. La sacarosa es la más empleada en los medios nutritivos (Cid 2010). Entre tanto, es posible que la sacarosa tenga presentado variación en las respuestas de algunas variables, no solamente por su propiedad de carbohidrato, pero también por su importante función de regulación osmótica en el medio de cultivo, controlando la relación de hidratación de los tejidos. Un estudio de Novero et al. (2010) con Metroxylon sagu indicó favorecimiento en el desarrollo de los tejidos en el medio de cultivo con elevada concentración de sacarosa, o en combinación entre la sacarosa y sorbitol. Los investigadores atribuyeron el mayor desarrollo de los tejidos al bajo potencial osmótico impuesto al medio de cultivo por la elevada concentración de solutos, aunque estos autores han trabajado con concentraciones de hasta 30 g.L.- .

La amplitud en la cantidad de sacarosa empleada en medios nutritivos es muy elevada y depende de varios factores. Las más altas concentraciones generalmente se utilizan en estudios con embriones, inducción de bulbillos o en la tuberización de raíces de yuca (Cid 2010). Sin embargo, se verificó que para diversas especies de palmeras, concentraciones de sacarosa arriba de los 30 g.L. $\mathrm{L}^{-1}$, lo más usual, tienen presentado resultados superiores. Un ejemplo importante es el trabajo de Nizam y Te-Chato (2009), en el cual el enraizamiento in vitro de plantas de Elaeis guineensis ocurrió de forma satisfactoria en el medio de cultivo WPM con 72 g.L. $\mathrm{L}^{-1}$ de sacarosa. Respuesta semejante se encontró en el estudio con enraizamiento de plantas de coquero-enano desarrollado por Lédo et al. (2007), donde se utilizaron $40 \mathrm{~g} . \mathrm{L}^{-1}$ de sacarosa en el medio Y3 (Eeuwens 1976) añadido de $1 \mathrm{mg} \cdot \mathrm{L}^{-1}$ del ANA, 0,5 mg. $\mathrm{L}^{-1}$ del BAP y $0,25 \%$ del carbón activo. 

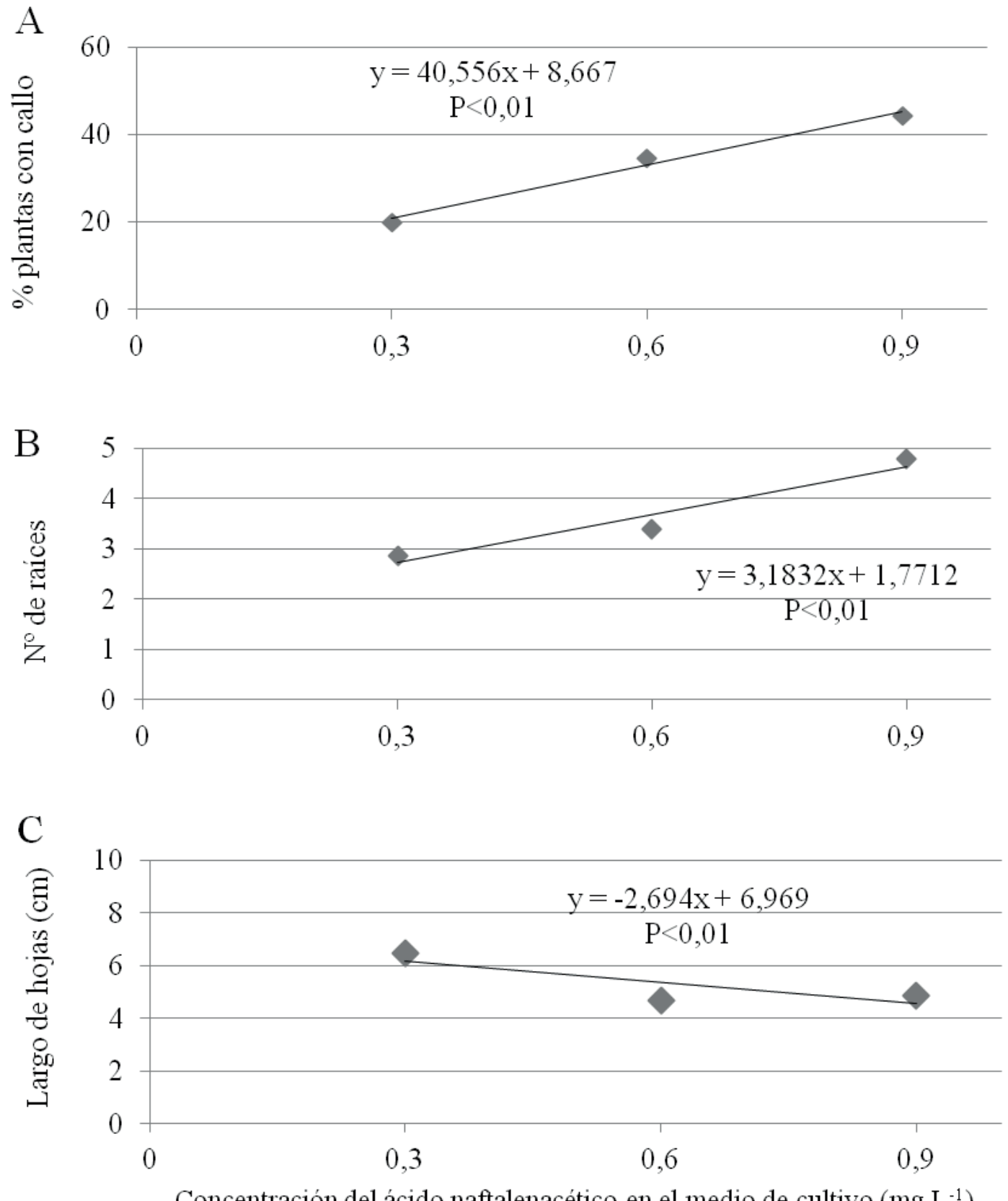

Concentración del ácido naftalenacético en el medio de cultivo (mg L $\left.{ }^{-1}\right)$

Figs. 3A-C. Enraizamiento in vitro de plantas de Butia odorata en medio de cultivo con 45 g.L $\mathrm{L}^{-1}$ de sacarosa y ácido naftalenacético a 0,$3 ; 0,6$ y 0,9 $\mathrm{mg} . \mathrm{L}^{-1}$. A. plantas con callo; B. número de raíces; C. largo de hojas.

Melo et al. (2001) estudiaron el AIB y el ANA (1 mg.L-1) en el enraizamiento in vitro de plantas de Syagrus oleraceae en el medio de cultivo MS con un $30 \mathrm{~g} . \mathrm{L}^{-1}$ de sacarosa. El ANA fue más eficiente generando raíces más largas, mayor peso de la materia fresca y seca. Entre tanto, en las variables correspondientes al desarrollo de la parte aérea no se verificó beneficios del empleo de las auxinas. Estos resultados corroboran la presente investigación, pues no se encontraron diferencias para esta variable en el primer estudio, mientras que en el tercer, en la concentración más alta de auxina se encontró plantas con hojas menos largas.
El porcentaje de plantas con callo y hojas senescentes aumentaron directamente con la concentración del ANA en el medio de cultivo $(\mathrm{P}<0,001)$. Posiblemente el proceso de calogénesis altera el metabolismo de los tejidos foliares, provocando la senescencia. Ese resultado ilustra la información respecto al efecto de la interacción que ocurre entre la auxina y el etileno en el metabolismo vegetal, pues, según Taiz \& Zeiger (2013), el etileno parece ser el principal regulador del proceso de abscisión foliar, con la auxina actuando como supresor del efecto del etileno. Entre tanto, concentraciones supra óptimas de auxina estimulan 
la producción de etileno, desencadenando el proceso de senescencia foliar, lo que probablemente tenga ocurrido en la presente investigación, pues la presencia de callos en regiones de la planta donde naturalmente hay formación exclusiva de raíces indica algún desequilibrio hormonal, en favor de la auxina.

Comparando los análisis de correlación del primer y tercer estudio, donde se probaron las concentraciones de ANA, se verificó que, en la mayoría de las variables, las correlaciones difieren de uno a otro (datos que no se muestran). Como ejemplo, en el primer estudio, donde se empleó la concentración del 20 g. $\mathrm{L}^{1}$ de sacarosa en el medio de cultivo, ocurrió correlación positiva entre peso fresco y largo de hojas, número de raíces, y plantas con callo. Sin embargo, en el tercer estudio, en el medio de cultivo con el 45 g. $\mathrm{L}^{-1}$ de sacarosa, estas variables no presentaron correlación significativa. Situación semejante se verificó entre las variables: número de raíces y porcentaje de enraizamiento; número de raíces y largo de hojas. Se verifica, por lo tanto, respuestas morfogénicas distintas en diferentes relaciones entre el ANA y la sacarosa.

Tras realizar una investigación buscando el enraizamiento in vitro de Phoenix dactylifera, Badawy et al. (2005) constataron que el número y el largo de las raíces aumentó proporcionalmente a la concentración de ANA (del 0,1 mg. $\mathrm{L}^{-1}$ hasta el 1,5 mg. $\mathrm{L}^{-1}$ ). Con 1,5 mg.L $\mathrm{L}^{-1}$ de ANA hubo formación de 2,5 raíces por planta, con largo medio de 3,0 cm. Entre tanto, la elevación de ANA para 4,5 mg. $\mathrm{L}^{-1}$ redujo significativamente, tanto el número de raíces cuanto su longitud.

Nizam \& Te-Chato (2009) cultivaron plantas de Elais guineensis obtenidos a partir de hojas jóvenes de plantas adultas, a los medios de cultivo MS, MS diluido y WPM con diferentes concentraciones de los fitorreguladores ANA y paclobutrazol (PBZ). Además de la proliferación de brotes, en la combinación de $6 \mathrm{mg} . \mathrm{L}^{-1}$ de ANA y 9 mg. $L^{-1}$ del PBZ ocurrió la formación de muchas raíces en un $88 \%$ de los explantes.

Comparándose los tres estudios, se verificó que la concentración de la auxina no afectó la variable largo de raíces. Sin embrago, las concentraciones de sacarosa se correlacionaron directamente con esa variable.

Hay relación significativa entre la cantidad de sacarosa disponible en el medio de cultivo y el desarrollo de raíces en palmeras. En estudios con Phoenix dactylifera, Badawy et al. (2005) obtuvieron respuestas superiores en la formación de raíces con concentraciones de sacarosa entre 30 y 40 g. $\mathrm{L}^{-1}$. Con $20 \mathrm{~g} \mathrm{~L}^{-1}$ se formaron raíces más cortas respecto a las demás concentraciones. Las raíces más largas se formaron en las plantas cultivadas en el medio de cultivo con 40 g.L. $\mathrm{L}^{-1}$ de sacarosa. Cuando se utilizó 50 g.L. $\mathrm{L}^{-1}$ de sacarosa el crecimiento de la parte aérea fue más pequeño comparándose a aquellos registrados bajo 30 y 40 g. $\mathrm{L}^{-1}$. Aunque se tratan de otras especies, estos resultados se parecen muchísimo con la presente investigación, pues se observó relación semejante para la variable largo de hojas y las concentraciones de sacarosa.
Asemota et al. (2007) sugieren el favorecimiento en el desarrollo de raíces de palmeras in vitro cuando estas se asocian a dosis elevadas de sacarosa y ANA. Según eses autores, la rizogénesis se promueve tras la interacción entre el ANA y la sacarosa. En estudios futuros se sugiere la ampliación de las concentraciones de la auxina, añadida de la sacarosa bajo concentraciones arriba del 30 g.L. $\mathrm{L}^{-1}$.

Basándose en los resultados obtenidos, plantones de Butia odorata mostraron enraizamiento satisfactorio in vitro en medio de cultivo con ácido naftalenacético entre 0,6 y $1,2 \mathrm{mg} . \mathrm{L}^{-1}$ añadido a concentraciones de sacarosa entre el 30 y 45 g.L. ${ }^{-1}$.

\section{REFERÉNCIAS}

Asemota, O., Eke, C.R. \& Odewale, J.O. 2007. Date palm (Phoenix dactylifera L.) in vitro morphogenesis in response to growth regulators, sucrose and nitrogen. African Journal of Biotechnology 6(20):2353-2357.

Badawy, E.M., Habid, A.M.A., El-Bana, A. \& Yosry, G.M. 2005. Propagation of date palm (Phoenix dactylifera) plants by using tissue culture technique. Arab Journal of Biotechnology 8:343-354.

Cid, L.P.B. 2010. Cultivo in vitro de plantas. Embrapa Informação Tecnológica, Brasília. 303p.

Eeuwens, C.J. 1976. Mineral requirements for growth and callus initiation of tissue explants excised from mature coconut palms (Cocos nucifera) and cultured in vitro. Physiologia Plantarum 36:23-28.

Fior, C.S., Rodrigues, L.R., Leonhardt, C. \& Schwarz, S.F. 2011. Superação de dormência em sementes de Butia capitata. Ciência Rural 41(7):1150-1153.

Fior, C.S., Souza, P.V.D. \& Schwarz, S.F. 2013. Emergência de plântulas de Butia odorata (Barb. Rodr.) Noblick em casa de vegetação. Revista Árvore 37(3):503-510.

Geymonat, G. \& Rocha, N. 2009. M'botiá. Ecosistema único en el mundo. Casa Ambiental, Castillos. 405 p.

Lédo, A.S., Gomes, K.K.P., Barboza, S.B.S.C., Vieira, G.S.S., Tupinambá, E.A. \& Aragão, W.M. 2007. Cultivo in vitro de embriões zigóticos e aclimatação de plântulas de coqueiro-anão. Pesquisa Agropecuária Brasileira 42(2):147-154.

Leitman, P., Henderson, A., Noblick, L. \& Martins, R.C. 2013. Arecaceae In Lista de Espécies da Flora do Brasil. Jardim Botânico do Rio de Janeiro. Disponible en: http://floradobrasil.jbrj.gov.br/jabot/ floradobrasil/FB53. Acceso en 12 mar. 2013.

Lorenzi, H., Kahn, F., Noblick, L.R. \& Ferreira, E. 2010. Flora brasileira Lorenzi: Arecaceae (Palmeiras). Instituto Plantarum, Nova Odessa. $367 \mathrm{p}$.

Marcato, A.C. 2004. Revisão taxonômica do gênero Butia (Becc.) Becc. e filogenia da subtribo Butiinae Saakov (Palmae). Tese 147 f., Universidade de São Paulo, São Paulo.

Meerow, A.W. \& Broschat, T.K. 2011. Container Production of Palms. University of Florida Bulletin CIR 1163. (2011). Disponible en: http://edis.ifas.ufl.edu/CN010. Acceso en nov. 2011.

Melo, B., Pinto, J.E.B.P., Luz, J.M.Q., Peixoto, J.R., \& Juliatti F.C. 2001. Efeito de ANA e AIB in vitro no enraizamento e crescimento da parte aérea da plântula da guarirobeira [Syagrus oleracea (Mart.) Becc.]. Bioscience Journal 17(1):49-59.

Murashige, T. \& Skoog, F. 1962. A revised medium for rapid growth and bioassays with tobacco tissue cultures. Physiologia Plantarum 15(3):473-497.

Nizam, K. \& Te-Chato, S. 2009. Optimizing of root induction in oil palm plantlets for acclimatization by some potent plant growth regulators (PGRs). Journal of Agricultural Technology 5(2):371-383.

Novero, A., Delima, A.G, Acaso, J. \& Baltores, L.M. 2010. The influence of osmotic concentration of media on the growth of sago palm (Metroxylon sagu Rottb.) in vitro. Australian Journal of Crop Science 4(6):453-456.

Pedron, F.A., Meneses, J.P. \& Meneses, N.L. 2004. Parâmetros biométricos de frutos, endocarpo e sementes de butiazeiro. Ciência Rural 34(2):585-586. 
Pillar, V.P., Müller, S.C., Castilhos, Z.M.S. \& Jacques, A.V. 2009. Campos Sulinos - conservação e uso sustentável da biodiversidade. Ministério do Meio Ambiente, Brasília. 403p.

Ribeiro, L.M., Neves, S.C., Silva, P.O., Andrade, I.G. \& Ribeiro, L.M. 2011. Germinação de embriões zigóticos e desenvolvimento in vitro de coquinho-azedo. Revista Ceres 58(2):133-139.

Rossato, M. 2007. Recursos genéticos de palmeiras do género Butia do Rio Grande do Sul. 2007. Tese 136 f., Universidade Federal de Pelotas, Pelotas.

Schlindwein, G.C.C.D. Schlindwein, A. Tonietto \& Dillenburg, L.R. 2013. Alleviation of seed dormancy in Butia odorata palm tree using drying and moist-warm stratification. Seed Science and Technology 41(1):1-11.

Taiz, L. \& Zeiger, E. 2013. Fisiologia Vegetal. Porto Alegre, Artmed. $954 \mathrm{p}$.

Tonietto, A., Schlindwein, G. \& Tonietto, S.M.. 2009. Usos e potencialidades do butiazeiro. Porto Alegre, Fundação Estadual de Pesquisa Agropecuária do Rio Grande do Sul. Circular Técnica 26:28.

Wang, H.C., Chen, J.T., Wu, S.P., Lin, M.C. \& Chang, W.C. 2003. Plant regeneration through shoot formation from callus of Areca catechu L. (Arecaceae). Plant Cell Tissue and Organ Culture 75(1):95-98. 